University of Nebraska - Lincoln

DigitalCommons@University of Nebraska - Lincoln

Weighing empirical and hypothetical evidence for assessing potential invasive species range limits: a review of the case of Burmese pythons in the USA

Richard M. Engeman

USDA-APHIS-Wildlife Services, s_r100@yahoo.com

Michael L. Avery

USDA, APHIS, Wildlife Services, michael.I.avery@aphis.usda.gov

Elliot Jacobson

University of Florida

Follow this and additional works at: https://digitalcommons.unl.edu/icwdm_usdanwrc

Part of the Life Sciences Commons

Engeman, Richard M.; Avery, Michael L.; and Jacobson, Elliot, "Weighing empirical and hypothetical evidence for assessing potential invasive species range limits: a review of the case of Burmese pythons in the USA" (2014). USDA National Wildlife Research Center - Staff Publications. 1456.

https://digitalcommons.unl.edu/icwdm_usdanwrc/1456

This Article is brought to you for free and open access by the U.S. Department of Agriculture: Animal and Plant Health Inspection Service at DigitalCommons@University of Nebraska - Lincoln. It has been accepted for inclusion in USDA National Wildlife Research Center - Staff Publications by an authorized administrator of DigitalCommons@University of Nebraska - Lincoln. 


\title{
Weighing empirical and hypothetical evidence for assessing potential invasive species range limits: a review of the case of Burmese pythons in the USA
}

\author{
Richard Engeman • Michael L. Avery • Elliott Jacobson
}

Received: 23 October 2013 / Accepted: 6 June 2014 / Published online: 19 June 2014

(C) Springer-Verlag Berlin Heidelberg (outside the USA) 2014

\begin{abstract}
Range expansion potential is an important consideration for prioritizing management actions against an invasive species. Understanding the potential for range expansion by invasive reptiles such as the Burmese python can be challenging, because the lack of knowledge on fundamental physiological and behavioral constraints initially forces reliance on modeling to predict hypothetical invasive range potential. Hypothetical predictions for Burmese python range limits in the USA have been highly divergent, from only extreme South Florida and the extreme southern Gulf edge of Texas to a broad swath over the southern third of the continental USA. Empirical observations on python thermal tolerances and behavioral abilities to cope with more temperate temperatures became evident during a cold spell in December 2009-January 2010. We review and highlight important considerations for improving invasive range estimation methodology, deciding between competing range predictions, and the importance of having, and applying, empirical data to aid in decision making.
\end{abstract}

Keywords Climate matching · Constrictor snakes . Physiological ecology $\cdot$ Python molurus bivittatus $\cdot$ Species distribution models $\cdot$ Thermal tolerances

Responsible editor: Philippe Garrigues

R. Engeman $(\bowtie)$

USDA, APHIS, Wildlife Services, National Wildlife Research Center, 4101 LaPorte Ave., Fort Collins, CO 80521-2154, USA

e-mail: richard.m.engeman@aphis.usda.gov

M. L. Avery

USDA, APHIS, Wildlife Services, National Wildlife Research

Center, 2820 East University Ave., Gainesville, FL 32641, USA

E. Jacobson

College of Veterinary Medicine, University of Florida, Gainesville,

FL 32610, USA

\section{Introduction}

Range expansion potential is an important consideration for prioritizing and developing management actions, policy, and rule making against invasive species. The Burmese python (Python molurus bivittatus), a well-established exotic species in the Everglades region of extreme southern Florida, is considered a major invasive species threat due to its large adult size (potentially $>5 \mathrm{~m}$ ) and the wide ranges in size and diversity of species as potential prey. These top-order carnivores are suspected of having serious impacts to native fauna, including endangered species, in the Everglades region (Dorcas et al. 2012; Dove et al. 2011; Greene et al. 2007; Snow et al. 2007a). Predicting the range expansion potential of the Burmese python can illuminate the potential breadth and magnitude of its impacts beyond South Florida.

Various range predictions for the Burmese python in the USA have been far from concordant (Jacobson et al. 2012; Pyron et al. 2008; Rodda et al. 2009; Van Wilgen et al. 2009). Here, we use the case of the Burmese python in Florida to examine issues concerning disparities among modeling results and between model predictions and available empirical information as well as concepts for making cogent choices in model development and for deciding among alternative range predictions.

\section{Brief background}

Burmese pythons arrived in South Florida through the pet trade, imported initially from the Bangkok, Thailand area, and subsequently (after 1994) from near Ho Chi Minh City, Vietnam (Barker and Barker 2008a, b; de Vosjoli and Klingenberg 2005). Burmese pythons have probably been breeding in the wild in South Florida for nearly a quarter century (Meshaka et al. 2000), with the invasion pathway 
largely attributed to (illegal) pet releases (see Hardin 2007 for a summary of legal rules concerning non-native species in Florida), although the highly destructive Hurricane Andrew in 1992 may also have released many from captive breeding and holding facilities (Bilger 2009; Hardin 2007; Snow et al. 2007b). The Florida pythons possess little genetic variability, and they appear to be distinct from Vietnam pythons (Collins et al. 2008), implying Thai origins (directly or indirectly) as the most plausible source for the Florida population. Additional DNA sequencing would be needed to determine the primary area(s) from which the Florida population originated.

As with most reptiles, the physiological thermal tolerances for Burmese pythons have not been experimentally defined. Considering that reptile species richness across the world can be mostly explained by temperature (Qian 2010), thermal tolerance information would be valuable for assessing range expansion potential. The critical thermal minimum, the low temperature where activity is impaired sufficiently to make survival unlikely, is especially important in this context (Avery 1982; Cowles and Bogert 1944; Huey 1982; Jacobson et al. 2012). Combined with physiological thermal tolerances, survival of a reptile depends on its behavioral flexibility in the face of thermal challenges. For the Burmese python to expand its range outside South Florida, the species must be able to tolerate or behaviorally protect itself from increasingly cold temperatures further north along the Florida peninsula and beyond into the rest of the USA mainland. Addressing the cooler temperatures may well pose a serious behavioral test for the species, because thermoregulation is relatively passive in the tropical and subtropical regions of Southeast Asia where the Burmese python is native, with ambient temperatures generally stable and supportive of normal activity throughout the year (Avery 1982; Huey 1982; Jacobson et al. 2012; Shine and Madsen 1996).

\section{Hypothetical correspondence between native climate and invasive range}

Because preferred optimum temperature ranges and thermal limits are undefined for most reptiles, climate matching is a commonly applied modeling technique for estimating the geographical limits and risk potential of an invasive species based on where it occurs in its native range (Engeman et al. 2011). Bomford et al. (2009) proposed that climate matching can be a valuable tool for assessing risk of establishment by alien herpetofauna, and many researchers have been exploring and evaluating attributes for assessing establishment risk (Bomford et al. 2009; Hayes and Barry 2008; Stohlgren and Schnase 2006). As with all statistics and modeling, the data upon which a model is generated and the analytical methods used to produce the results determine the accuracy and utility of inferences (Engeman et al. 2011). Thus, it is essential to accurately define the appropriate native climate data to use in range predictions. Different models have been used to infer possible limits of Burmese python distribution in the continental USA and have produced widely divergent range predictions (Jacobson et al. 2012; Pyron et al. 2008; Rodda et al. 2009; Van Wilgen et al. 2009).

Three of these modeling efforts (Pyron et al. 2008; Rodda et al. 2009; Van Wilgen et al. 2009) based their analyses on climate information from localities within and near the combined native distribution of the Burmese python and the closely related Indian python (P. molurus molurus). It should be noted that even though the Burmese python has been considered a subspecies of the same species as the Indian python, the two were distinguished legally, with the Indian python having been listed as an endangered species since 1976 (USDI/U.S. Fish and Wildlife Service 1976) and not imported to the USA since 1972 (Barker and Barker 2008b). It should also be noted that the Burmese python, originally described as a distinct species in 1820 (Barker and Barker 2008a), has alternated between being classified as a distinct species and being classified as a subspecies within P. molurus (see Barker and Barker 2008a for a brief classification history), with the subspecies classification being accepted since 1930 (Barker and Barker 2008a). Recently, articles have appeared suggesting designation of Burmese and Indian pythons as distinct species (Jacobs et al. 2009; Reynolds et al. 2013), although a genomic study is needed using adequate sampling and accurate sequencing from multiple populations of each snake to establish whether or not they can be considered distinct species.

Rodda et al. (2009, originally published online in 2008) used temperature and rainfall data to generate a hypothetical range of suitable habitat covering a large swath of the southern third of the USA from coast to coast. Similarly, Van Wilgen et al. (2009) used bioclimatic modeling to predict Burmese python potential range to also include much of the southeast USA and the Pacific Northwest coast of the USA and Canada. Pyron et al. (2008) used ecological niche modeling to infer southern Florida and the very southern extremity of Texas as the only suitable habitat for Burmese pythons in the USA. Rodda et al. (2011) later critiqued Pyron et al. (2008) on technical merit. Ignoring the potential for faults among the models (see "Range model approaches, pitfalls, and model selection"), their radically divergent results make it difficult to know which result, if any, should be trusted for decision-making purposes. As we discuss later, empirical data form the most dependable asset for discriminating among competing model outputs.

\section{Combining physiological tolerance projections with empirical observations}

In contrast to strictly hypothetical climate modeling approaches, Jacobson et al. (2012) analyzed the question of cold 
tolerance and potential range expansion by integrating multiple hypothetical and empirical factors:

1. Postulated minimum temperatures for python digestion, activity, and survival;

2. Daily low and high temperatures recorded from October through February 2005-2011 from four sites (Homestead, Orlando, and Gainesville, FL, and Aiken, SC);

3. Recent empirical reports on overwinter mortality of Burmese python in the Everglades, Gainesville, FL, and Aiken, SC; and

4. Empirical observations on whether Burmese pythons possess behaviors and physiology to cope with and survive winter temperatures.

Assimilating all factors of physiological and behavioral function with historical norms and extremes in current and possible colonization localities, they concluded that it is unlikely that Burmese pythons would be able to expand to or colonize areas beyond their current range in South Florida.

\section{Empirical observations}

Range predictions based on hypothetical climate models or estimates of thermal tolerances are just that, hypothetical. Until empirical data are available for testing which prediction is most accurate, there is no certain means to know whether a prediction has merit. A prolonged cold front in the southern USA during December 2009-January 2010 enabled testing of model range predictions and provided valuable empirical thermal tolerance information for Burmese pythons (Jacobson et al. 2012).

In January 2010, Mazzotti et al. (2011) were using radiotelemetry to monitor activity of 10 Burmese pythons in the heart of their invasive range in Everglades National Park. During this period, ambient temperatures recorded at Homestead Air Reserve Base (just east of Everglades National Park) were colder than normal (Jacobson et al. 2012). Following the period of cold temperatures, nine of the 10 monitored pythons were found dead or near dead (Mazzotti et al. 2011), indicating a large portion of the wild population may have died in the cold.

During this same cold spell, Avery et al. (2010) found that, even with refugia and heat sources, adult Burmese pythons did not demonstrate behavioral or physiological abilities to survive cold weather events in the central Florida peninsula, $400 \mathrm{~km}$ north of their introduced range in the Everglades area. During 2-12 January $2010,47 \%$ of hourly ambient temperatures recorded in Gainesville, FL, were $\leq 0{ }^{\circ} \mathrm{C}$ (Avery et al. 2010). Of nine adult Burmese pythons maintained in individual outdoor enclosures with shelter and a heat source, only two snakes stayed in their heated hide boxes and survived exposure to the cold temperatures (Avery et al. 2010).

Dorcas et al. (2011) tested whether Burmese pythons could survive in the more temperate climates predicted by Rodda et al. (2009) as suitable for possible colonization. They released 10 wild-caught male pythons from Everglades National Park in June 2009 into a near-natural enclosure in Aiken, SC. The same cold front that severely impacted the Florida pythons simultaneously passed through South Carolina. However, temperatures in South Carolina are colder than those in Florida, and eight of the 10 pythons died in cold temperatures in December 2009 prior to the severe cold front in January 2010 when the final two of the pythons were found dead (Dorcas et al. 2011).

For these studies, subfreezing temperatures resulted in python mortality regardless of whether snakes had access to refugia with above-freezing temperatures. Any pythons living north of the Everglades appeared to have a poor chance for survival. As documented by radiotelemetry, even pythons in the Everglades had a high risk of mortality (Mazzotti et al. 2011).

The behavioral observations by Avery et al. (2010) and Mazzotti et al. (2011) were congruent with those of Barker (2008) that tropical constrictors, including Burmese pythons, do not display a survival instinct for avoiding lethally cold temperatures. The Burmese python, as a mostly tropical and subtropical species, apparently does not recognize potentially lethal cold. Instead, it appears to increase basking to counter lower temperatures (Avery et al. 2010; Barker 2008), effective for increasing body temperature within the limited breadth of ambient temperatures in their native range, but placing them at risk in more temperate climes (Jacobson et al. 2012).

\section{Range model approaches, pitfalls, and model selection}

When no solid understanding exists for predicting the potential range of an invasive species, hypothetical predictions are often based on the climate characteristics of the native range. The hypothetical predictions for potential range of Burmese pythons in the USA are very disparate, and there is no fixed protocol that will lead to certain accuracy for predicting range expansion by an introduced species. The disparate predictions of invasive potential of the Burmese python demonstrate that data sources and modeling factors greatly influence range predictions. Common sense guidelines can contribute to, but not guarantee, accuracy. Incorporating climate data from localities distant from the source population and combining native range data from multiple taxa likely lead to a propagation of errors when predicting invasive range potential (Engeman et al. 2011; Jacobson et al. 2012).

Occam's razor (e.g., Baker 2007), the principle encouraging the selection of the hypothesis requiring the fewest 
assumptions, might be applied to selecting among competing hypothetical range predictions. The most parsimonious explanation of python range potential would be that a genetically homogeneous invasive population of a tropical/subtropical species would populate only areas environmentally similar to its area of origin. To assume such a species would expand its range beyond such circumstances requires acceptance of increasingly unlikely combinations of assumptions. First, the species would have to be assumed to have increasingly greater physiological tolerances (critical thermal minimum) for survival as the climate becomes more temperate. Second, the species would also have to be assumed to have increasingly broader behavioral characteristics for survival as climate becomes more temperate (e.g., hibernation versus basking in lethally cold conditions). Third, even if the species was behaviorally programmed to seek shelter from the cold, assumptions would have to be made concerning sufficient availability of refugia with adequate size, depth, and moisture content to ensure protection of very large snakes from freezing temperatures and dehydration. While Occam's razor can serve as a scientific tiebreaker among hypotheses (i.e., three hypothetical models with a paucity of empirical data), empirical data for assessing model adequacy are of greater definitive virtue (Baker 2007). From either perspective, the most conservative of the range predictions for Burmese pythons in the USA appears to be the most plausible. That is, the hypothetical range prediction with the most parsimonious assumptions (most conservative range predictions) corresponded well with the empirical observations of Burmese pythons experiencing local temperature extremes. The empirical evidence from the cold spell also demonstrated that extreme daily temperature changes rather than, or in addition to, monthly mean temperatures need to be factored into climate-based models for defining areas at risk of invasion (Avery et al. 2010; Engeman et al. 2011).

Accurate assessment of the native range based on actual record locations is essential for developing climate data from native ranges. Obtaining accurate data representations of where a species occurs in its native range along with associated weather data seems to be relatively simple in concept but is open to pitfalls. For example, one potential error would be to assume that a species occurs throughout the area loosely connected by boundary lines within which record locations occur, as this makes it impossible to associate with certainty a weather station to a specific area in which the species is found. Another potential trap would be to strictly consider species record locations and meteorological stations based on twodimensional map distances without also considering intervening three-dimensional altitudinal topographies, as this could greatly bias the climate data for the native range (e.g., Engeman et al. 2011). Furthermore, Jacobson et al. (2012) suggest developing distribution models that link spatial data with physiological responses of the species to its environment (e.g., Kearney and Porter 2009), although this approach requires information on species physiological ecology which often is not available.

Jeschke and Strayer (2008) assert that "the general usefulness of bioclimatic models is unclear." They point out in particular that bioclimatic models are often applied but rarely tested. Further, bioclimatic models form the first of the following two general model categories for predicting potential invasive ranges (Jeschke and Strayer 2008):

1. Models that statistically compare climatic variables (e.g., temperature, precipitation, etc.) between locations, also referred to as correlative models (Dormann et al. 2012), as contrasted with

2. Models based on species' tolerances to environmental factors (e.g., critical thermal minimum and maximum) which are often determined in laboratory settings. These can also be considered as process-based models (Dormann et al. 2012).

The models of Pyron et al. (2008), Rodda et al. (2009), and Van Wilgen et al. (2009) fall in the former category, while the approach of Jacobson et al. (2012) falls more into the latter category.

Model performance for predicting range spread by an invasive species is best tested using independent data, which typically are not readily available (Jeschke and Strayer 2008). The January 2010 cold spell offered the first rigorous independent test data for assessing performance of bioclimatic models predicting the potential range of Burmese pythons. The most conservative model (Pyron et al. 2008) corresponded best to the empirical observations.

In adaptive management (Holling 1978; Stankey et al. 2005; Walters 1986), methods evolve as an iterative process; information acquired in association with management actions is incorporated to improve future management actions. For models, an adaptive strategy improves predictions as foundational flaws in modeling assumptions or procedures are discovered and/or as tests of model estimates become available through acquisition of empirical data (e.g., Bromberg et al. 2011; Cianfrani et al. 2010; Jones 2012). This approach serves to improve prediction by reducing structural and parametric uncertainty arising from incomplete (or inaccurate) knowledge about the modeled system (Runge et al. 2011).

As an example, the efforts of Pyron et al. (2008) could be considered as an iterative update of the existing model efforts by Rodda et al. (2009), which was originally published online in 2008 (hence the dates of the cited papers), as they stated that their efforts were motivated in part to correct some of the native climate issues found in Rodda et al. (2009). Pyron et al. (2008) did this by basing their analyses only on the actual locality presence information (for Burmese and Indian pythons combined), rather than the data from weather stations 
presumed to be within the envelope of their native range(s) as applied by Rodda et al. (2009). The results of Pyron et al. (2008) approximated well the current invasive range of Burmese pythons in extreme South Florida. In general for this and the other correlative models, further refinements using known locality presence data only for the Burmese python and inclusion of empirical information on the lethality of the January 2010 cold spell would potentially further increase their model accuracy. In the case of the process-based model, Jacobson et al. (2012) presented their results with knowledge of the cold spell's effects on pythons; their efforts likely could be improved with experimentally determined thermal tolerances for Burmese pythons rather than applying conservatively hypothesized figures.

Besides iteratively updating a particular type of model using improved information, it may also be possible to combine different models to form an ensemble model (e.g., Crossman and Bass 2008; Jones et al. 2010) as a means of increasing confidence in results. Creating a single type of model is difficult, so it is natural that creating an ensemble model would be more so, as already indicated for linking spatial distribution models with physiological responses of the species to its environment (Jacobson et al. 2012; Kearney and Porter 2009). Moreover, errors in underlying models can cause errors in composite models, further highlighting the need to iteratively update the underlying models as improved information and methods become available.

\section{Discussion}

Prevention is the most efficient and economical means to control invasive species (e.g., NISC 2001), and a variety of steps have been taken to reduce the number of introductions in Florida, with some apparent success (Hardin 2007). The soundest approaches for estimating range limits of an invasive species would be of most value to managers and policy makers for deciding the best course(s) of action for managing the species. In congruence with the empirical data from the associated inherent test of the hypothetical range predictions by the cold front, Burmese pythons are considered by Florida authorities as a problem not extending beyond Florida's subtropical climate (e.g., Nolen 2012). In contrast, the U.S. Fish and Wildlife Service listed the Burmese python and three other large constrictor snakes as nationally injurious invasive species under the Lacey Act, making it illegal to import or transport them across state lines. Battling the species' spread in the USA has been featured prominently in the reasoning for this action (Nolen 2012).

Florida's subtropical climate in the south, its major ports of entry for many wildlife species to the USA (both legal and illegal), its thriving captive wildlife industry, and its location in an area of destructive hurricanes that can release captive animals make the state especially susceptible to the introduction and establishment of a wide range of species (e.g., Corn et al. 2002; Hardin 2007). Moreover, Florida is isolated from land with similar climates, resulting in the state's native vertebrates typically originating in the southeast USA at the southern extremes of their ranges. Invaders to Florida therefore find relatively fewer native species to contend with than in most tropical/subtropical locations (Hardin 2007). Not surprisingly, Florida and Hawaii have the most severe invasive species problems in the USA (U.S. Congress 1993; Corn et al. 2002). Florida has more introduced animals than any other regions of the USA and also ranks high in this respect globally (Hardin 2007). It stands to reason that exotic species will continually become introduced and established in Florida. In developing invasive species management priorities, it is not only important to gain insight into potential ecological impacts but to assess a species' potential for range expansion in a sound manner.

\section{References}

Avery RA (1982) Field studies of body temperatures and thermoregulation. In: Gans C, Pough FH (eds) Biology of the Reptilia, vol 12. Academic Press, New York, pp 93-166

Avery ML, Engeman RM, Keacher KL, Humphrey JS, Bruce WE, Mathies TC, Mauldin RE (2010) Cold weather and the potential range of invasive Burmese pythons. Biol Invasions 12:3649-3652

Baker A (2007) Occam's razor in science: a case study from biogeography. Biol Philos 22:193-215

Barker DG (2008) Will they come in out of the cold? Observations of large constrictors in cool and cold conditions. Bull Chicago Herpetol Soc 43:93-97

Barker DG, Barker TM (2008a) The distribution of the Burmese python, Python molurus bivittatus. Bull Chicago Herpetol Soc 43:33-38

Barker DG, Barker TM (2008b) Comments on a flawed herpetological paper and an improper and damaging news release from a government agency. Bull Chicago Herpetol Soc 43:45-47

Bilger B (2009) Swamp things. The New Yorker 20:80-89

Bomford M, Kraus F, Barry S, Lawrence E (2009) Predicting establishment success for alien reptiles and amphibians: a role for climate matching. Biol Invasions 11:713-724

Bromberg JE, Kumar S, Brown CS, Stohlgren TJ (2011) Distributional changes and range predictions of downy brome (Bromus tectorum) in Rocky Mountain National Park. Invasive Plant Sci Manag 4:173182

Cianfrani C, Le Lay G, Hirzel AH, Loy A (2010) Do habitat suitability models reliably predict the recovery areas of threatened species? J Appl Ecol 47:421-430

Collins TM, Freeman B, Snow S (2008) Final report genetic characterization of populations of the nonindigenous Burmese python in Everglades National Park. Final report for the South Florida Water Management District. Department of Biological Sciences. Florida International University, Miami, $30 \mathrm{p}$

Corn ML, Buck EH, Rawson J, Segarra A, Fischer E (2002) Invasive non-native species: background and issues for congress. Congressional Research Service and The Library of Congress, Washington, DC 
Cowles RB, Bogert C (1944) A preliminary study of the thermal requirements of desert reptiles. Bull Am Mus Nat Hist 83:265-296

Crossman ND, Bass DA (2008) Application of common predictive habitat techniques for post-border weed risk management. Divers Distrib 14:213-224

de Vosjoli P, Klingenberg R (2005) Burmese python plus reticulated pythons and related species. Advanced Vivarium Systems, Irvine, CA

Dorcas ME, Willson JD, Gibbons JW (2011) Can invasive Burmese pythons inhabit temperate regions of the southeastern United States? Biol Invasions 13:793-802

Dorcas ME, Willson JD, Reed RN, Snow RW, Rochford MR et al (2012) Severe mammal declines coincide with proliferation of invasive Burmese pythons in Everglades National Park. Proc. Natl Acad Sci 109:2418-2422

Dormann CF, Dormann CF, Schymanski SJ, Cabral J, Chuine I, Graham C, Hartig F, Kearney M, Morin X, Römermann C, Schröder B, Singer A (2012) Correlation and process in species distribution models: bridging a Dichotomy. J Biogeogr 39:2119-2131

Dove CJ, Snow RW, Rochford MR, Mazotti FJ (2011) Birds consumed by the invasive Burmese python (Python molurus bivittatus) in Everglades National Park, Florida, USA. Wilson J Ornithol 123: 126-131

Engeman RM, Jacobson E, Avery ML, Meshaka WE Jr (2011) The aggressive invasion of exotic reptiles in Florida with a focus on prominent species: a review. Curr Zool 57:599-612

Greene DU, Potts JM, Duquesnel JG, Snow RW (2007) Geographic distribution: Python molurus bivittatus (Burmese python). Herpetol Rev 38:355

Hardin S (2007) Managing non-native wildlife in Florida: state perspective, policy and practice. In: Witmer G, Pitt W, Fagerstone K (eds) Managing vertebrate invasive species: proceedings of an international symposium. USDA/APHIS/WS. National Wildlife Research Center, Fort Collins, CO, pp 43-52

Hayes KR, Barry SC (2008) Are there any consistent predictors of invasion success? Biol Invasions 10:483-506

Holling CS (1978) Adaptive environmental assessment and management. Wiley, Chichester

Huey R (1982) Temperature, physiology, and the ecology of reptiles. In: Gans C, Pough FH (eds) Biology of the Reptilia, vol 12. Academic Press, New York, pp 25-67

Jacobs HJ, Auliya M, Böhme W (2009) Zur taxonomie des dunklen tigerpythons, Python molurus bivittatus Kuhl, 1820, speziell der population von Sulawesi. Sauria 31:5-16

Jacobson ER, Barker D, Barker T, Mauldin R, Avery ML, Engeman RM, Secor S (2012) Environmental temperatures, physiology, and behavior limit the range expansion of invasive Burmese pythons in the southeastern U.S. Integr Zool 7:271-285

Jeschke JM, Strayer DL (2008) Usefulness of bioclimatic models for studying climate change and invasive species. Ann. N.Y. Acad Sci 1134:1-24

Jones CC (2012) Challenges in predicting the future distributions of invasive plant species. For Ecol Manag 284:69-77

Jones CC, Acker SA, Halpern CB (2010) Combining local- and largescale models to predict the distributions of invasive plant species. Ecol Appl 20:311-326

Kearney M, Porter W (2009) Mechanistic niche modelling: combining physiological and spatial data to predict species ranges. Ecol Lett 12: $1-7$
Mazzotti FJ, Cherkiss MS, Hart KM, Snow RW, Rochford MR, Dorcas ME, Reed RN (2011) Cold-induced mortality of invasive Burmese pythons in south Florida. Biol Invasion 13:143-151

Meshaka WE Jr, Loftus WF, Steiner T (2000) The herpetofauna of Everglades National Park. Florida Sci 63:84-103

NISC (National Invasive Species Council) (2001) Meeting the invasive species challenge: National Invasive Species Management Plan. National Invasive Species Council, Washington, DC

Nolen RS (2012) How big is Florida's python problem? J Am Vet Med Assoc 240:778-782

Pyron RA, Burbrink FT, Guiher TJ (2008) Claims of potential expansion throughout the U.S. by invasive python species are contradicted by ecological niche models. PLoS One 3:e2931

Qian H (2010) Environment-richness relationships for mammals, birds, reptiles, and amphibians at global and regional scales. Ecol Res 25: 629-637

Reynolds RG, Niemiller ML, Revell RJ (2013) Toward a tree-of-life for the boas and pythons: multilocus species-level phylogeny with unprecedented taxon sampling. Mol Phylogenet Evol. doi:10. 1016/j.ympev.2013.11.011

Rodda GH, Jarnevich CS, Reed RN (2009) What parts of the US mainland are climatically suitable for invasive alien pythons spreading from Everglades National Park? Biol Invasion 11:241-252

Rodda GH, Jarnevich CS, Reed RN (2011) Challenges in identifying sites climatically matched to the native ranges of animal invaders. PLoS One 6(2):e14670

Runge MC, Converse SJ, Lyons JE (2011) Which uncertainty? Using expert elicitation and expected value of information to design an adaptive program. Biol Conserv 144:1214-1223

Shine R, Madsen T (1996) Is thermoregulation unimportant for most reptiles? An example using water pythons (Liasis fuscus) in tropical Australia. Physiol Zool 69:252-269

Snow RW, Brien ML, Cherkiss MS, Wilkins L, Mazzotti FJ (2007a) Dietary habits of the Burmese python, Python molurus bivittatus, in Everglades National Park, FL. Herpetol Bull 101:5-7

Snow RW, Krysko KL, Enge KM, Oberhofer L, Walker-Bradley A, Wilkins L (2007b) Introduced populations of Boa constrictor (Boidae) and Python molurus bivittatus (Pythonidae) in southern Florida. In: Henderson RW, Powell R (eds) The biology of boas and pythons. Eagle Mountain Publishing, Eagle Mountain, UT, pp 416438

Stankey GH, Clark RN, Bormann BT (2005) Adaptive management of natural resources: theory, concepts, and management institutions. Gen. Tech. Rep. PNW-GTR-654. U.S. Department of Agriculture, Forest Service. Pacific Northwest Research Station, Portland, OR

Stohlgren TJ, Schnase JL (2006) Risk analysis for biological hazards: what we need to know about invasive species. Risk Anal 26:163173

U.S. Congress (1993) Harmful non-indigenous species in the United States. Office of Technology Assessment, OTA-F-565. Government Printing Office, Washington DC

USDI/U.S. Fish and Wildlife Service (1976) Endangered status for 159 taxa of animals. Fed Regist 41:24062-24067

Van Wilgen NJ, Roura-Pascual N, Richardson DM (2009) A quantitative climate-match score for risk assessment screening of reptile and amphibians introductions. Environ Manag 44:590-607

Walters CJ (1986) Adaptive management of renewable resources. McGraw Hill, New York 